ISSN : 2722-9289

http://ejournal.poltekkes-smg.ac.id/ojs/index.php/J-SiKep

\title{
The Influence Spiritual Emotional Freedom Technique (SEFT) Therapy To Decrease The Intensity Of Post Operative Pain In Major Surgery Patients In Hospital Dr . R. Soeprapto Cepu
}

\author{
M. Zainal Abidin ${ }^{1} *$ Siswanto $^{2}$ Agus Prasetyo ${ }^{3}$ Hartatik $^{4}$ \\ ${ }^{1,2,3,4}$ Program Studi D-III Keperawatan Blora, Poltekkes Kemenkes Semarang, Indonesia
}

*Corresponding author : M. Zainal Abidin

Email: zainalabidinoke@gmail.com

Received: July 28, 2020; Revised: August 12, 2020; Accepted: August 29, 2020

\begin{abstract}
The operation is an action that is always associated with the incision so it would to be pain. Therefore, the management of non-pharmacological measures the change in the intensity of postoperative pain in patients considered to be very important and helpful. One of them is the SEFT therapy (Spiritual Emotional Freedom Technique). Based on preliminary studies that SEFT therapy has not been used to help reduce pain in postoperative patients. The purpose of this study was to analyze the effect of therapy SEFT to decrease pain intensity in patients with postoperative major surgery in hospital Dr. R. Soeprapto Cepu. This type of research using experiment with design Static Pre - Group Comparison. In this study, the sampling technique used was purposive sampling with a sample of 44 respondents. Results of Mann Whitney test respondents pain intensity p value $0.017(<0.05)$. Based on the research results, it can be concluded that there SEFT therapeutic effect on reduction of pain intensity in patients with postoperative major surgery in hospital Dr. R Soeprapto Cepu, so it is advisable to provide therapy should SEFT with more frequency and time so that the decrease in the intensity of postoperative pain in major surgery patients can be maximized.
\end{abstract}

Keyword : Post Operations; SEFT; Pain Intensity

\section{Introduction \\ (Pendahuluan)}

Nyeri pasca operasi merupakan masalah pada penderita yang mengalami pembedahan. Dampak nyeri jika tidak ditangani secara baik dapat memunculkan hal-hal negatif seperti menimbulkan gangguan pada sistem pernafasan, kardiovaskuler, muskuloskeletal dan mobilitas pasien.Oleh karena itu dibutuhkan penanganan yang tepat, baik secara farmakologi maupun non farmakologi. ${ }^{14}$

Nyeri bersifat subjektif dan tidak ada individu yang mengalami nyeri yang sama. Untuk itu perawat perlu mencari pendekatan yang paling efektif dalam upaya pengontrolan nyeri. ${ }^{13}$

Data di RS Dr. R. Soeprapto Cepu pada tahun 2017 menunjukkan sebanyak 597 kasus (20\%) pasien yang menjalani operasi, data tahun 2018 sebanyak 888 kasus (24\%) orang dan pada tahun 2019, tercatat mulai bulan Januari sampai September 2019 sebanyak 988 orang yang menjalani operasi dimana rata-rata setiap bulannya 110 orang (Data Rekam Medik RS Dr. R. Soeprapto Cepu, 2019).

Menurut Walsh dalam Harnawatiaj (2008) pada pasien post operasi seringkali mengalami nyeri hebat meskipun tersedia obat-obat analgesik yang efektif, namun nyeri pasca bedah tidak dapat diatasi dengan baik, sekitar $50 \%$ pasien tetap mengalami nyeri sehingga dapat mengganggu kenyamanan pasien. Karena itulah penatalaksanaan tindakan non farmakologi dalam perubahan intensitas nyeri pada pasien post operasi dianggap sangat penting dan membantu. Salah satunya yaitu dengan terapi SEFT (Spiritual Emosional Freedom Technique).

SEFT (Spiritual Emosional Freedom Technique) merupakan suatu terapi psikologi yang pertama kali ditujukan untuk melengkapi alat psikoterapi yang sudah ada.SEFT adalah gabungan 
antara Spiritual Power dan Energy Psychology. SEFT bekerja dengan prinsip yang kurang lebih sama dengan akupuntur dan akupressur. Ketiga teknik ini berusaha merangsang titik-titik kunci di sepanjang 12 jalur energi (energi meridian) tubuh yang sangat berpengaruh pada kesehatan kita (Faiz, 2012).Teknik SEFT ini berfokus pada kata atau kalimat tertentu yang diucapkan berulang kali dengan ritme yang teratur disertai sikap pasrah pada Tuhan sesuai dengan keyakinan responden.

Sehubungan dengan hal tersebut, maka peneliti merasa tertarik untuk melakukan penelitian tentang "Pengaruh Terapi Spiritual Emotional Freedom Technique (SEFT) Terhadap Penurunan Intensitas Nyeri Pada Pasien Post Operasi Bedah Mayor di RS. Dr. R. Soeprapto Cepu".

Adapun tujuan umum dalam penelitian ini adalah mengetahui pengaruh Terapi SEFT (Spiritual Emotional Freedom Technique) terhadap penurunan intensitas nyeri pada pasien post operasi bedah mayor di RS. Dr. R. Soeprapto Cepu. Sedangkan tujuan khususnya adalah mengidentifikasi karakteristik responden penelitian meliputi usia, jenis kelamin, suku bangsa dan status perkawinan, mengetahui intensitas nyeri pada pasien post operasi tanpa dilakukan terapi SEFT (Spiritual Emotional Freedom Technique), mengetahui intensitas nyeri pada pasien post operasi dengan dilakukan terapi SEFT dan menganalisa pengaruh terapi SEFT terhadap penurunan intensitas nyeri pada pasien post operasi. Tujuan dari penelitian ini adalah untuk mengetahui pengaruh Terapi SEFT (Spiritual Emotional Freedom Technique) terhadap penurunan intensitas nyeri pada pasien post operasi bedah mayor di RS. Dr. R. Soeprapto Cepu

\section{Methods (Metode Penelitian)}

Jenis penelitian yang digunakan dalam penelitian ini adalah penelitian kuantitatif. Design penelitian yang digunakan adalah Pre Eksperiment dengan rancangan Static-Group Comparison. Dalam penelitian ini sebagian kelompok diberikan perlakuan sesuai dengan metode yang dikehendaki, dan sebagian yang lain tidak diberikan perlakuan, kemudian dibandingkan hasil pengukuran akhirnya. $^{2}$

Sampel dalam penelitian ini diambil dengan metode purposive sampling, yaitu pengambilan sampel berdasarkan pada suatu pertimbangan tertentu yang dibuat oleh peneliti sendiri, berdasarkan ciri atau sifat- sifat populasi yang sudah diketahui sebelumnya. ${ }^{10}$ Teknik ini dilakukan dengan pertimbangan dan tujuan tertentu diantaranya waktu, biaya, tenaga dan dana sehingga tidak dapat mengambil sampel yang besar dan jauh. ${ }^{1}$

Penentuan besar sampel berdasarkan pertimbangan menurut Arikunto (2006). Berdasarkan hasil perhitungan, jumlah sampel adalah 44. Pada masing-masing kelompok kontrol dan kelompok perlakuan dalam penelitian ini adalah 22 responden pasien post operasi bedah mayor di RSUD. Dr. R. Soeprapto Cepu.

Alat pengumpul data dalam penelitian ini adalah peneliti menggunakan lembar observasi dan checklist yang berisi prosedur pelaksanaan SEFT (Spiritual Emosional Freedom Technique). Sedangkan untuk lembar observasi tentang intensitas nyeri peneliti mengadopsi dari teori Numerical Rating Scale 0-10 oleh Manskoski, 1995; Rockvill,1992 dengan skala rasio 0-10.

Sedangkan hasil penelitian dilakukan pengolahan data dengan analisa univariat yaitu untuk menganalisa karakteristik dari responden yang meliputi umur, jenis kelamin, suku bangsa dan status pernikahan serta intensitas nyeri responden pada kelompok kontrol dan kelompok perlakuan, yang pada umumnya dalam analisis ini menghasilkan distribusi dan prosentase dari setiap variabel. Analisa Bivariat dilakukan terhadap dua variabel dan diduga berhubungan atau berkorelasi (Notoatmodjo, 2010). Dalam penelitian ini analisa bivariat digunakan untuk mengetahui pengaruh terapi SEFT (Spiritual Emotional Freedom Technique) terhadap intensitas nyeri dengan menggunakan uji Mann Whitney. Nilai keyakinan yang dipahami dalam uji statistik adalah 0,95 dan nilai kemaknaan $\alpha=0,05$ (Notoatmodjo, 2002). Ha diterima apabila $\mathrm{p}$-value $<0,05$.

\section{Results and Discussion (Hasil dan Pembahasan)}

\begin{tabular}{|c|c|c|c|c|c|c|}
\hline & \multicolumn{2}{|c|}{$\begin{array}{l}\text { Kelompok } \\
\text { Perlakuan }\end{array}$} & \multicolumn{2}{|c|}{$\begin{array}{c}\text { Kelompok } \\
\text { Kontrol }\end{array}$} & \multicolumn{2}{|c|}{ Jumlah } \\
\hline & $\mathrm{n}$ & $(\%)$ & $\mathrm{n}$ & $(\%)$ & $\mathrm{n}$ & $(\%)$ \\
\hline Umur & & & & & & \\
\hline $17-30$ th & 4 & 18,1 & 5 & 22,7 & 9 & 21 \\
\hline $31-50$ th & 10 & 45,5 & 10 & 45,5 & 20 & 46 \\
\hline$>50$ th & 8 & 36,4 & 7 & 31,8 & 15 & 34 \\
\hline $\begin{array}{c}\text { Jenis } \\
\text { Kelamin }\end{array}$ & & & & & & \\
\hline Laki-laki & 12 & 54,5 & 13 & 59,1 & 25 & 57 \\
\hline Perempuan & 10 & 45,5 & 9 & 40,9 & 19 & 43 \\
\hline $\begin{array}{c}\text { Suku } \\
\text { Bangsa }\end{array}$ & & & & & & \\
\hline Jawa & 22 & 100 & 22 & 100 & 44 & 100 \\
\hline $\begin{array}{c}\text { Status } \\
\text { Pernikahan } \\
\text { Kawin }\end{array}$ & 19 & 86,4 & 18 & 81,8 & 37 & 84 \\
\hline
\end{tabular}




\begin{tabular}{ccccccc}
\hline & \multicolumn{2}{c}{$\begin{array}{c}\text { Kelompok } \\
\text { Perlakuan }\end{array}$} & \multicolumn{2}{c}{ Kelompok } & \multicolumn{2}{c}{ Kontrol } \\
\cline { 2 - 7 } & $\mathrm{n}$ & $(\%)$ & $\mathrm{n}$ & $(\%)$ & $\mathrm{n}$ & $(\%)$ \\
\hline $\begin{array}{c}\text { Tidak } \\
\text { Kawin }\end{array}$ & 3 & 13,6 & 4 & 18,2 & 7 & 16 \\
\hline
\end{tabular}

Tabel 1 menunjukkan bahwa pada kelompok perlakuan sebagian besar responden terdapat pada rentang umur 31-50 tahun sebanyak 10 responden $(45,5 \%)$, umur $>50$ tahun sebanyak 8 responden $(36,4 \%)$ dan sebagian kecil umur 17-30 tahun sebanyak 4 responden (18,2\%). Sedangkan pada kelompok kontrol sebagian besar responden terdapat pada rentang umur 31-50 tahun sebanyak 10 responden $(45,5 \%)$, umur $>50$ tahun sebanyak 7 responden $(31,8 \%)$ dan sebagian kecil umur 17-30 tahun sebanyak 5 responden (22,7\%).

Kelompok perlakuan sebagian besar responden dengan jenis kelamin laki-laki sebanyak 12 responden $(54,4 \%)$ dan hanya 10 responden $(45,5 \%)$ dengan jenis kelamin perempuan. Sedangkan pada kelompok kontrol sebagian besar responden dengan jenis kelamin laki-laki sebanyak 13 responden $(59,1 \%)$ dan sebagian kecil dengan jenis kelamin perempuan sebanyak 9 responden $(40,9 \%)$.

Kelompok perlakuan dan kelompok kontrol semua respoden dengan suku bangsa Jawa yaitu masing-masing sebanyak 22 responden (100\%).

Kelompok perlakuan sebagian besar status pernikahannya adalah kawin sebanyak 19 responden $(86,4 \%)$ dan hanya 3 responden $(13,6 \%)$ dengan status pernikahannya tidak kawin. Sedangkan pada kelompok kontrol sebagian besar status pernikahannya adalah kawin sebanyak 18 responden $(81,8 \%)$ dan hanya 4 responden $(18,2 \%)$ dengan status pernikahannya tidak kawin.

\section{Intensitas Nyeri Pada Pasien Post Operasi Bedah Mayor}

Tabel 2. Distribusi Intensitas Nyeri

Kelompok Perlakuan dan Kelompok Kontrol

\begin{tabular}{ccccccc}
\hline \multirow{2}{*}{$\begin{array}{c}\text { Intensitas } \\
\text { Nyeri }\end{array}$} & \multicolumn{2}{c}{$\begin{array}{c}\text { Kelompok } \\
\text { Perlakuan }\end{array}$} & \multicolumn{2}{c}{$\begin{array}{c}\text { Kelompok } \\
\text { Kontrol }\end{array}$} & \multicolumn{2}{c}{ Jumlah } \\
\cline { 2 - 7 } & $\mathrm{n}$ & $(\%)$ & $\mathrm{n}$ & $(\%)$ & $\mathrm{n}$ & $(\%)$ \\
\hline $\begin{array}{c}\text { Nyeri } \\
\text { ringan }\end{array}$ & 16 & 72,7 & 8 & 36,4 & 24 & 56 \\
$\begin{array}{c}\text { Nyeri } \\
\text { sedang }\end{array}$ & 6 & 27,3 & 14 & 63,6 & 20 & 44 \\
\hline
\end{tabular}

Intensitas nyeri pada pasien post operasi bedah mayor tanpa pemberian terapi SEFT (Spiritual Emotional Freedom Technique).

Hasil penelitian menunjukkan bahwa pada kelompok kontrol sebagian besar intensitas nyerinya adalah dengan nyeri sedang sebanyak 14 responden $(63,6 \%)$ dan hanya 8 responden $(36,4 \%)$ dengan nyeri ringan.

Hal ini dapat diketahui bahwa pada kelompok kontrol intensitas nyerinya tidak menunjukkan penurunan yang bermakna, hal tersebut dikarenakan pada kelompok kontrol tidak diberikan perlakuan untuk menurunkan intensitas nyerinya baik dengan teknik distraksi maupun teknik relaksasi yang lain yang dapat menurunkan intensitas nyeri.

Nyeri yang dialami responden diakibatkan oleh nociceptor stimuli selama tindakan pembedahan. Nyeri post operasi dapat dirasakan mulai hari pertama sampai dengan tiga hari post operatif, responden mengalami nyeri level sedang sampai berat tergantung pada tipe pembedahan.

Hasil penelitian sesuai dengan hasil penelitian sebelumnya oleh Megawati (2010), bahwa pasien pasca laparatomi pada hari kedua mengeluhkan nyeri sedang dengan skala 4-7 sebanyak $57,70 \%$, yang mengeluhkan nyeri berat diatas 7 sebanyak $15,38 \%$, dan nyeri ringan sebanyak $26,92 \%$. Pada penelitian yang dilakukan oleh Wijayati Sugih, Ngadiyon, Hardjanti Triana Sri (2013), mendapati bahwa metode SEFT dapat memberikan relaksasi dan penurunan intensitas nyeri pada pasien Post Sectio Caesaria.

Terapi SEFT merupakan pengobatan alternatif untuk mengurangi nyeri dismenore primer, karena terapi ini relatif aman dan tidak menggunakan obat-obatan, sebagaimana hasil penelitian yang dilakukan oleh Hidayanti Desi, Legiati Titi, Purwaningsih Dewi (2018).

Nyeri merupakan respon fisiologis terhadap kerusakan jaringan dan juga mempengaruhi respon emosional dan tingkah laku, berdasarkan pengalaman nyeri seseorang dimasa lalu dan persepsi terhadap nyeri. ${ }^{14}$ 
Intensitas nyeri dengan pemberian terapi SEFT (Spiritual Emotional Freedom Technique) pada pasien post operasi bedah mayor

Berdasarkan hasil penelitian menunjukkan bahwa sebagian besar intesitas nyeri responden pada kelompok perlakuan dengan pemberian terapi SEFT (Spiritual Emotional Freedom Technique)adalah dengan nyeri ringan sebanyak 16 responden $(72,7 \%)$ dan hanya 6 responden $(27,3 \%)$ dengan nyeri sedang.

Hasil penelitian dapat diketahui bahwa dengan pemberian SEFT (Spiritual Emotional Freedom Technique) terjadi penurunan intensitas yang cukup bermakna.Hal ini dikarenakan pada saat responden dilakukan terapi SEFT (Spiritual Emotional Freedom Technique) mampu memfokuskan perhatiannya pada nyeri dan responden tidak mengalami kecemasan yang dapat meningkatkan persepsinya terhadap nyeri, sehingga skala nyeri menjadi menurun.

Pemberian terapi SEFT (Spiritual Emotional Freedom Technique) memberikan stimulasi sistem energi tubuh yang berhubungan langsung dengan sumber rasa sakit, pengaktifan jalur pressure nyeri, sehingga akan mengaktifkan perangsangan listrik di substansia grisea serebri. Mengaktifkan dan menstimulasi pengeluaran neurotransmitter analgesia alamiah (endorphin, enkhepalin, dinorphin) dalam rangka memblokade substansia $P$ sebagai neurotransmiter nyeri.Rasa nyeri yang timbul dapat di hambat dengan penekanan substansia P. ${ }^{12,13,16}$

\section{Perbedaan nilai rerata intensitas nyeri}

\begin{tabular}{cccccc}
\multicolumn{6}{c}{ Tabel 3. Perbedaan Rerata Intensitas Nyeri } \\
\hline & N & Min & Max & Mean & $\begin{array}{c}\text { Std. } \\
\text { Deviation }\end{array}$ \\
\hline $\begin{array}{c}\text { Kelompok } \\
\text { Kontrol }\end{array}$ & 22 & 3 & 5 & 3,95 & 0,844 \\
$\begin{array}{c}\text { Kelompok } \\
\text { Perlakuan }\end{array}$ & 22 & 2 & 4 & 3,14 & 0,640 \\
\hline Selisih & & & & 0,81 & \\
\hline
\end{tabular}

Pengaruh Terapi SEFT (Spiritual Emotional Freedom Technique) Terhadap Penurunan Intensitas Nyeri Pada Pasien Post Operasi Bedah Mayor di RS. Dr. R. Soeprapto Cepu.

Tabel 4. Pengaruh SEFT Terhadap Penurunan Intensitas Nyeri

\begin{tabular}{lccc}
\hline & $\mathrm{N}$ & $\mathrm{Z}$ & $\begin{array}{c}\text { Asymp. Sig. } \\
\text { (2-tailed) }\end{array}$ \\
\hline $\begin{array}{l}\text { Intensitas nyeri } \\
\text { pre test-post test }\end{array}$ & 22 & -2.394 & 0,017 \\
\hline
\end{tabular}

Hasil penelitian menunjukkan bahwa hasil uji Mann Whitney intensitas nyeri responden didapatkan nilai $Z_{\text {hitung }}=-2.394$ $\left(>Z_{\text {tabel }}=1.645\right)$ dan nilai p $0,017(<0,05)$ sehingga dapat diambil kesimpulan bahwa $\mathrm{Ha}$ diterima yaitu ada pengaruh terapi SEFT (Spiritual Emotional Freedom Technique) terhadap penurunan intensitas nyeri pada pasien post operasi bedah mayor di RSUD Dr. R Soeprapto Cepu.

Berdasarkan hasil penelitian juga dapat diketahui bahwa terdapat perbedaan nilai rerata antara kelompok kontrol dengan kelompok perlakuan sebesar 0,81. Hal ini menunjukkan bahwa pada kelompok perlakuan terjadi penurunan intensitas nyeri yang signifikan dibandingkan dengan penurunan intensitas nyeri pada kelompok kontrol. Temuan fakta ini menunjukkan bahwa pemberian SEFT (Spiritual Emotional Freedom Technique) dapat menurunkan intensitas skala nyeri pada orang dengan post operasi bedah mayor.

Hasilpenelitian sesuai dengan teori bahwa impuls nyeri dihantarkan saat sebuah pertahanan dibuka dan impuls dihambat saat sebuah pertahanan ditutup. Merangsang $\beta$ endorfin merupakan salah satu cara untuk menutup mekanisme pertahanan sehingga menghambat pelepasan substansi $\mathrm{P}$ yang merupakan salah satu transmiter nyeri. Seperti yang dipaparkan di atas bahwa terapi SEFT sama-sama dapat merangsang peningkatan $\beta$ endorfin yang disuplai oleh tubuh.Sehingga pada saat neuron nyeri perifer mengirimkan sinyal ke sinaps, terjadi sinapsis antara neuron perifer dan neuron yang menuju otak tempat seharusnya substansi $\mathrm{P}$ akan menghantarkan impuls. Pada saat tersebut, $\beta$-endorfin akan 
memblokir lepasnya substansi $\mathrm{P}$ dari neuron sensorik sehingga transmisi impuls nyeri di medula spinalis menjadi terhambat dan sensasi nyeri berkurang. ${ }^{18}$

\section{Conclusion \\ (Simpulan)}

Terdapat pengaruh terapi SEFT (Spiritual Emotional Freedom Technique) terhadap penurunan intensitas nyeri pada pasien post operasi bedah mayor.

\section{References (Daftar Pustaka)}

1. Arikunto, S., (2006). Prosedur Penelitian Suatu Pendekatan Praktik. Jakarta :Rineka Cipta.

2. Aziz, AlimulHidayat (2008). Metode Penelitian Keoerawatan dan Tehnik Analisis Data.Salemba Medika :Jakarta.

3. Brunner dan Suddart (2002). Keperawatan Medikal Bedahpenerjemah Panggabean. Jakarta: EGC.

4. Efendy (2005). Kiat Sukses Menghadapi Operasi. Yogyakarta: Sahabat Setia.

5. Faiz, Zainuddin (2012). Spiritual Emotional Freedom Technique For Healing, Succes,Happiness, Greatness. Edisi Revisi. Jakarta: Afzan Publishing

6. Harnawatiaj (2008). Nyeri. http:// harnawatiaj.wordpress.com/2008/05/05/nyeri/ . Diakses tanggal 10 Desember 2019.

7. Hidayanti Desi, Legiati Titi, Purwaningsih Dewi (2018). The Effect Of Spiritual Emotional Freedom Technique (Seft) Therapy On Primary Dysmenorrhea Intensity, Proceeding of The 1st International Conference on Interprofessional Health Collaboration and Community Empowerment, Vol 1 No 1

8. Ma'rifah Atun Raudatul,dkk (2018). The Effectiveness of Fingerhold Relaxation o And Spiritual Emosional Freedom Technique (Seft) To The Pain Intensity Scale On Patients With Post Caesarean Section, http://www.mcrhjournal.or.id/index.php/jmcrh /article/view/28/31

9. Megawati.(2010). Pengaruh SEFT dalam Penurunan Nyeri Kronis.Unpublished. Moewardi, Surakarta

10. Notoadmodjo (2010). Metode Penelitian Kesehatan.Jakarta : Rineka Cipta.
11. Nursalam (2008). Konsep dan Penerapan Metodologi Penelitian Ilmu Keperawatan:Pedoman Skripsi, Tesis, dan Instrumen Penelitian Keperawatan. Jakarta : Salemba Medika

12. Potter, P \& Perry, A. G (2005).Buku Ajar Fundamental Keperawatan : Konsep,Proses, dan Praktik, E/4, Vol 1. Jakarta : EGC.

13. Potter, P \& Perry, A. G (2006).Buku Ajar Fundamental Keperawatan : Konsep,Proses, dan Praktik, E/4, Vol 2. Jakarta : EGC.

14. Smeltzer, S.C. \& Bare, B.G (2002).Buku Ajar Keperawatan Medikal Bedah. Brunner and Suddarth (8th edition) : editor, Suzanne. C. Smeltzer, Brenda G. Bare ; Ahli Bahasa, Agung Waluyo, dkk, editor bahasa Indonesia, Monica Ester, Ellen Pangabean. Jakarta : EGC.

15. Sjamsuhidajat \& Wim de Jong (2005). Buku Ajar Ilmu Bedah.Edisi revisi.Jakarta : EGC.

16. Syaputra (2000). Akupunktur dalam pendekatan ilmukedokteran.Edisi pertama.Surabaya: AirlanggaUniversit Press.

17. Wijayati Sugih, Ngadiyon, Hardjanti Triana Sri (2013). Relaxation Methods To Reduce Pain And Injuries Seft Post Sectio Caesaria,http:/lejournal.poltekkessmg.ac.id lojs/index.php/jrk/article/view/390.

18. Yuniarsih, Sri Mumpuni (2010). Perbandingan Intervensi Spiritual Dan Spiritual Emotional Freedom Technique (Seft) Terhadap Penurunan Intensitas Nyeri Dan Kecemasan Ibu Bersalin Kala I Di Puskesmas Poned Kota Pekalongan.Diakses http://cisral.unpad.ac.id. Diakses Tanggal 27 Nopember 2019. 